Copyright $(\subset 2018$ by the Kalmyk Scientific Center of the Russian Academy of Sciences

Published in the Russian Federation
Oriental Studies (Previous Name: Bulletin
Humanities of the Russian Academy of Scient
Has been issued as a journal since 2008
ISSN: 2619-0990; E-ISSN: 2619-1008
Vol. 38, Is. 4, pp. 75-85, 2018
DOI 10.22162/2619-0990-2018-38-4-75-85
Journal homepage: https://kigiran.elpub.ru

УДК 39

\title{
«А «плохую» шею мы оставим дома...» (о символике шейных позвонков в свадебной обрядности
}

\section{калмыков)*}

Татьяна Исаевна Шараева ${ }^{1}$

${ }^{1}$ старший научный сотрудник, отдел истории, этнологии и археологии, Калмыцкий научный центр PAH (358000, Россия, г. Элиста, ул. им. И.К.Илишкина, д. 8). ORCID: 0000-0002-22425136. E-mail: sharaevati@yandex.ru

Аннотация. В статье рассматривается символика шейных позвонков барана в свадебной обрядности калмыков. В современной свадебной обрядности шейные позвонки барана всегда оставляют в пределах домашнего пространства, что объясняется существованием поверья о них как о «плохом» мясе, которое не годится для обрядовой трапезы, а может быть употреблено только в качестве повседневной пищи. В различных источниках по обрядовой культуре калмыков нет сведений и пояснений о шейных позвонках барана и ритуальных действиях с ними. Привлечение сравнительно-сопоставительного материала по свадебной обрядности тюрко-монгольских народов позволило выявить семантику шейных позвонков ритуального животного и реконструировать обрядовые действия с ними в канве традиционной свадебной обрядности калмыков.

В обрядовой культуре тюрко-монгольских народов, в том числе калмыков, семь шейных позвонков отождествляются с образом предка, с семью поколениями предков и близких родственников, а атлант - с предком-основателем рода. Многочисленные примеры использования частей бараньей туши в различных свадебных обрядах указывают, что через них и «воссоздание» тела предка достигается взаимосвязь для испрашивания покровительства, наделения витальностью, чадородием от него, налаживание связей, необходимых для семейной жизни новобрачных, с божествами и покровителями различных уровней.

Мы пришли к выводу, что локализация шейных позвонков в качестве подношения в пространстве традиционного жилища во время проведения свадьбы у калмыков была обусловлена представлениями о взаимосвязи жертвенного животного с культом предков и существовавшими онгонами, практика изготовления которых была искоренена буддизмом к концу XIX в. В канве традиционной свадебной обрядности считалось, что посредством действий с шейными позвонками можно достичь контакта с предками для испрашивания жизненности, чадородия и покровительства. В современной калмыцкой свадебной обрядности отсутствие обрядовых действий с шеей животного и оставление только в семейном пространстве является утратой первоначальных знаний о ней вследствие табуации.

Ключевые слова: калмыки, свадебная обрядность, зоолатрические культы, баран, шейные позвонки

* Исследование проведено в рамках государственной субсидии - проект «Комплексное исследование этнических культур монголоязычных народов в условиях социокультурного взаимодействия» (№ госрегистрации 115062510041). 
Современная свадебная обрядность калмыков включает значительно трансформированные обряды и ритуалы традиционного комплекса, которые, несмотря на изменения самой структуры свадьбы, исчезновение некоторых этапов, обусловленных кочевым бытом, и объединение в настоящее время других, сохраняют социализирующее значение, мировоззренческие представления, закрепляют новые родственные связи, отображают этническое своеобразие.

Отправляясь за невестой, представители свадебного поезда жениха берут с собой:

1) кисломолочный продукт цุаһан идән, водку, сладости, масло в качестве ритуального угощения для получения разрешения на вход в дом родителей невесты - зәңг оруллин (букв. калм. 'внесение вести');

2) баранью голову, обернутую внутренним жиром, сладости, мучные изделия борцоги (боориг), масло и молоко - для подношения божествам (дееж);

3) борцоги, сладости, вино - угощение для снох рода жениха (берәчүдин хөв);

4) пачку чая, молоко, масло для приготовления чая и бутылку водки - для ритуального благословения, окропления и вкушения, что означает благословление приданого невесты - өвин цз (букв. калм. 'чай приданого');

5) кроме того, везут большое количество борцогов, сладостей, оговоренное количество спиртных напитков (количество водки, вина, коньяка или шампанского зависит от приданого невесты), вареное мясо барана и одну живую овцу для совершения обряда жертвоприношения огню - hал тәәлин.

Как и прежде, при доставлении частей вареной бараньей туши обращается внимание на то, чтобы все ее части были в наличии, так как отсутствие одной из них могло осложнить положение, «вызвать отсрочку свадьбы и даже отказ принимать прибывших гостей» [Эрдниев 1970: 195].

Части сваренной бараньей туши укладывают в анатомическом порядке: сначала кладут задние ноги, крестец, сердце, печень, обернутую внутренним жиром, желудок с кровью, почки, обе части ребер, грудинку, обе передние ноги, голени (три, одну оставляют дома) и баранью голову без нижней челюсти и языка. При разделывании туши следят за целостностью костей, поэтому ее разделяют на части при помощи только ножа по сочленениям.
Необходимо отметить, что существуют незначительные варианты, обусловленные родовыми традициями: везут четыре голени, а не три, баранью голову везут целой, не удаляя нижнюю челюсть, вместо вышеуказанных значимых внутренностей доставляют только зөр $м^{l}$ - нанизанные на тонкую обструганную палочку кусочки внутренностей, которые, согласно народным представлениям, связаны с понятиями витальности, чадородия, родственных связей и эмоций [Шараева 2015: 74-84].

Несмотря на существование представлений об обязательном доставлении всех частей бараньей (или овечьей) туши, что связано с зоолатрическими культами и мифологическими мотивами об умирающем и воскресающем животном в этнической картине мира у калмыков, шейные позвонки всегда оставляют в пределах домашнего пространства. С чем это связано? Почему везут все части туши животного, кроме шеи? Оставление шейных позвонков объясняется существованием поверья о них как о «плохом» мясе, которое не годится для обрядовой трапезы, а может быть употреблено только в качестве повседневной пищи. В различных источниках по обрядовой культуре калмыков нет сведений и пояснений о шейных позвонках барана и ритуальных

1 Состав зөрм может быть различным: кусочки 1) печени, легкого, почки, сердца, прямой кишки; 2) того же, но сверху обмотанные внутренним жиром семжн; 3) печени, прямой кишки, рубца; 4) печени, легкого, почки, сердца, прямой кишки, внутреннего жира, которые сверху обмотаны тонко нарезанными полосами из рубца так, чтобы оставался один длинный конец, выступающий по центру полученного «кокона»; 5) печени, легкого, брыжейки, сычуга и кусочек мяса с грудинки өрчин махн. В повседневной практике приготовления бараньих внутренностей дотр (=дотур) термином зөрм называют тонкие кишки барана нәрн гесн, сложенные так, что их форма напоминает «косичку». Для этого один конец кишки зажимают большим и указательным пальцами левой руки и наматывают оставшуюся часть на ладонь так, чтобы диаметр образовавшегося круга составлял примерно 1520 см. Таким способом наматывают на ладонь с напуском всю тонкую кишку, оставляя длинный конец. Оставшейся частью «плетут косичку» зөрм: из-под обмотанной части на ладони выводят петлю, из нее следующую и т. д., пока плетение не закончится. Конец кишки вытягивают из последней петли для ее закрепления. 
действиях с ними. Возникает вопрос: «Почему в современной калмыцкой обрядовой культуре с шейными позвонками барана связано такое поверье?».

Если обратиться к свадебной обрядности тюрко-монгольских народов, то можно выделить определенные значимые обряды с использованием шейных позвонков. Так, у баятов Монголии, по сведениям А. Очир и Г. Р. Галдановой, молодым вручали шейную часть барана перед брачной ночью. Ее заранее отваривали и подвешивали на верхний конец (головку) толгой правой стенки юрты. Каждый из новобрачных трижды откусывал кусок мяса и съедал, после этого их укладывали на брачном ложе, на котором заранее были постелены друг на друга три войлочные подстилки невесты и три войлочные подстилки жениха. Подголовник клали в изголовье, непременно обратив лицевой стороной к очагу, затем молодоженов накрывали одеялом. Этот обряд назывался «соединение подголовников» (дэр нийлуулэх) [Очир, Галданова 1992: 47-48].

Сходным с описанным был обряд дэр нийлуулэх у алтайских урянхайцев. «Перед брачной ночью на кровати молодых застилали три войлочных подстилки невесты с каймой зеленого цвета, поверх них - три с каймой красного цвета жениха. Большой подголовник $u x$ дэр клали в изголовье, обратив лицевой стороной к очагу, всё накрывали одеялом. Новобрачных сажали на подготовленное ложе и подавали им сваренный шейный позвонок барана, который был заранее подвешен к верхнему концу правой стенки юрты (ханын толгой). Каждый из молодых трижды откусывал кусочек мяса. После этого молодых укладывали и накрывали одеялом» [Лхагвасурэн 2013: 126-127].

В современном калмыцком языке терминами дер негдүлх (букв. 'соединять подушки'), толһа негдүлх (букв. 'соединять головы'), толһаһан ниилүлх (букв. 'сливаться головами') маркируется собственно свадьба (хүрм). О желающих вступить в брак говорят: эдн толһаһан ниилүлх седжсәнд (букв. 'они хотят слить головы' (слиться головами), дерән негдүлх седжсәнә (букв. ' хотят объединить подушки').

Термином дерән ниилүлх обозначается в канве современной свадебной обрядности обряд шитья подушки молодоженов дерин haдр уйлhн: со стороны жениха привозят подушку, отрез ткани для изготовления наволочки на нее, нитки, иголки, масло, спирт- ное для совершения ритуала благословения готовой подушки. Вариантом обряда является изготовление наволочки для двух сложенных вместе подушек: одну привозит с собой жених, другую берут из приданого невесты. В данном случае подразумевается и «соединение» подушек, и союз молодоженов, и сам факт происходящей свадьбы.

После шитья наволочки глава свадебного кортежа жениха хүрмин ахлач обмазывает четыре конца подушки сливочным маслом и произносит благопожелание. В этом обрядовом действии проявляется символическая «продуцирующая функция» подушки, которая, как считается, символизирует супружеское ложе. Данный обряд, вероятно, является остаточным проявлением изготовления приданого невесты совместно родными брачующихся, который в традиционной свадебной обрядности завершал цикл предсвадебных обрядов ${ }^{1}$.

Вместо традиционной войлочной подстилки щирдг в настоящее время используют современные матрасы небольшого размера для совершения ритуала поклонения невесты на пороге дома родителей жениха. Согласно свадебным традициям XIX в., при проведении обрядов принятия невесты она должна была сидеть на белой двойной подстилке, которую привозила с собой. На этой же подстилке усаживали жениха и невесту при проведении обряда бракосочетания. Белый цвет подстилки символизировал невинность и чистоту помыслов, войлок - плодовитость, а ее двуслойность семантически приравнивалась к соединению двух судеб.

После совершения обрядов эту войлочную подстилку помещали на постель новобрачных. Современные матрасы, использовавшиеся в ритуале поклонения невесты на пороге родительского дома, впоследствии используются калмыками в быту только членами семьи. Можно предположить, что войлочная подстилка как атрибут

1 Для изготовления приданого, выбрав благоприятный день, прибывали с подарками и угощением мать жениха и 4-5 женщин. С собой они привозили шкуры, ткани, принадлежности для шитья. Раскрой вещей производился в день прибытия, пошив занимал несколько дней. За это время изготавливалось несколько комплектов зимней и летней одежды замужней женщины, постельные принадлежности и предметы быта, как, например, волосяные и шерстяные веревки для установки войлочного жилища, кожаные сосуды для молока и хранения чая и т. д. 
обряда могла сменить сырую шкуру барана, специально забитого для свадебного ритуала. Этот обычай был характерен для тюркомонгольских народов и назывался «вхождение в огонь», так как шкура использовалась для обрядов поклонения огню очага, во время проведения которых невеста садилась на расстеленную сырую шкуру барана около огня со стороны порога [Обряды 2002: 133].

По данным К. В. Вяткиной, у монголов «перед возвращением свадебного поезда жениха молодые должны войти в жилище родителей невесты, где накануне им были оставлены шейные позвонки. С приходом молодых их кладут в белый мешочек и дают трижды надкусить. При этом отец невесты в этот момент должен держать баранью голову с сердцем зүлд (здесь, вероятно, подразумевается весь ливер зүлд - неразделенные трахея, сердце, печень, легкие. - $T$. Ш.)» [Вяткина 1960: 209]. Дополнительно в работе К. В. Вяткиной в разделе «Народные предания, поверья, предания и легенды» есть сведения, что «когда кто-либо женится, то на обед в течение трех дней должны варить шейные позвонки, мясом с которых молодой муж делится с женой. Это означает, что жизнь молодых должна быть такой же крепкой, как шея животного» [Вяткина 1960: 244]. Эти сведения даны без указания, представители какой этнической группы придерживаются данной традиции.

В канве традиционной свадебной обрядности калмыков обряд жертвоприношения огню проводился и на стороне невесты, и на стороне жениха, что было связано с обрядами отделения и обрядами принятия невесты из одного рода в другой, представлениями о ритуальной «смерти» невесты в своем роду и «возрождении» ее в новом, в том числе через «реинкарнацию жертвы» во время обряда жертвоприношения огню - hал тәәлһн.

Представители субэтнических групп дербетов и торгутов проводили обряд haл тәәлhн на стороне невесты в день отъезда свадебного поезда на сторону жениха, у хошутов, свадебный комплекс которых имел много матрилокальных черт, согласно сведениям П. Небольсина, совершался в хотоне невесты после обряда бракосочетания перед брачной ночью [Небольсин 1852: 76]. На стороне жениха у дербетов и торгутов обряд hал тәәлин проводился после проведения основных обрядов и ритуалов приобщения невесты к роду жениха.
Ритуальные составляющие и действия в обряде и у невесты, и у жениха имели сходные черты, основной целью было призывание души к перерождению через подношение жертвы огню ритуальным животным. В XIX в. калмыки при проведении данного обряда в белый мешок укладывали знаковые части туши животного далгана махн (сердце, печень, двенадцатиперстная кишка, прямая кишка, диафрагма, сычуг, жир с грудной клетки) и подвешивали их над семейной кроватью; подвешивалась правая передняя нога далгана ха под кроватью «между кошмой и жердью»; нижнюю половину головы и крестцовую часть устанавливали в качестве подношения божествам дееж [Душан 2016: 319]. И. Житецкий в описании жертвоприношения огню на свадьбе указывал, что «...отец спинную часть с курдюком и голову барана ставит в табык перед бурханами; первый шейный позвонок (подчеркнуто мной. $-T$. $Ш$.) кладет в „бурхани оргёее под унину под кошму; легкие, сердце, почки, печень, заднепроходную кишку, сваренный и наполненный кровью желудок $<\ldots>$, шкуру с груди с жиром, предварительно опаленную, кладет в какую-нибудь посуду или в овчинную шубу или в сумку из кожи» [Житецкий 1893: 24], затем делает круг вокруг жертвенного костра.

Во время чтения молитв и совершения призывания $х ү р Y$ взмахами рук участниками обряда мать берёт правую переднюю ногу животного, которая висела на унине (жердь для установки дымохода) рядом с алтарем, и передает ее по кругу посолонь. После обряда «...ногу сырую снова вешают в ,бурхани орьге ес, где она должна оставаться три дня, мешок с внутренностями держат спрятанным в сундуке до другого дня, когда все разрезают на куски по числу кибиток в хотоне и съедают $<\ldots>$ кроме желудка с кровью, который хранят три дня. Через три дня желудок и ногу съедает семья и родственники жениха» [Житецкий 1893: 24].

В современной свадебной обрядности калмыков правую переднюю ногу используют в цикле послесвадебных обрядов: при совершении жертвоприношения доставленной на свадьбу овцой через несколько дней после свадьбы сырую правую ногу вручают снохе, которая должна сидеть во время обряда на полу, расстелив подол своей одежды. В отсутствии практики надевания традиционного костюма замужней женщины в настоящее время, ей надевают верхнюю 
одежду или халат свекрови, что, вероятно, символизирует смену статуса и наличие одежды замужней женщины. Во время обряда сноха должна совершать трижды круговые движения хүрүлх этой бараньей ногой, установив ее копытом на подол своей одежды, предварительно вложив монету в раздвоенную часть копыта животного. Подобные обрядовые действия считаются обращением к предкам для принятия вновь прибывшего члена семьи под покровительство и «закреплением» его на новой территории.

Во время забоя тушу барана калмыки разделяют на следующие части: грудинку, две передних ноги с 12 ребрами и плечевыми костями, две задних ноги, спинную часть и шею [Эрендженов 1980: 76]. Голову и ливер (калм. зүлд - неразделенные при разделке трахея мөөрсн, печень элкн, легкие оошк, сердце зүркн) выделяют в настоящее время по отдельности, что противоречит традиции. Отделенные ливерные части вместе с промытыми внутренностями используют для приготовления блюда дотр (=дотур).

Спинную часть туши животного составляют шейные позвонки күзүн (первый позвонок - атлант, у основания черепа; второй - аксис, который позволяет поворачивать голову; с третьего по шестой (калм. сер-күзүн) - шея), грудные позвонки с седьмого шейного до поясничных әмннурhн, крестец с семью крупными поясничными позвонками ууц, хвост сүл. При проведении обряда жертвоприношения огню hал mәәлһн, имеющего и календарное, и семейное значения, разделка туши ритуального животного производится по суставам.

С отваренных частей туши хозяин дома, в котором проводится обряд, должен отделить первый шейный позвонок как символ крепости семьи. Мясо с этого позвонка должны есть все представители мужской части рода. Шея, крестец с хвостом и грудинка отвариваются отдельно для совершения подношения божествам дееж, а в обрядовых действиях шея, левая передняя и правая задняя нога барана являются символами всего животного [Бакаева 2009: 90].

В повседневной жизни из шейных позвонков готовят бульон, который, как считается, получается наваристым и калорийным и в случае заболевания и ослабления организма человека может положительно воздействовать на него. Мясо с шейных по- звонков, которого обычно бывает немного, съедают глава семьи и его жена, могут дать детям; вышедшим замуж дочерям и их детям не дают. Небольшое количество мяса на позвонках либо обгрызается, либо полностью срезается небольшим ножом (букв. күзY мөлжсх 'грызть зубами кости шеи').

У саянских тюрков первый шейный позвонок, два первых правых ребра и бедренную кость обязательно варили вместе с первым блюдом свежего мяса. Первые два ребра и атлант никто не имел права кушать, кроме хозяина - иначе не будет плодиться скот. Существовал строгий запрет на поедание мяса шейных позвонков детьми, так как существовало поверье, что от съеденного у них будет болеть шея.

Сваренную шею животного необходимо обгладывать, не пользуясь ножом. Мужчина произносил заклинание: «Ты, вожак черной головы, ты, младший шейный позвонок, в трудную минуту не бросай, если упаду не калечься. Атлант никогда не выбрасывали на улицу, а хранили дома. Хозяин в нем видел оберег своей головы. При перекочевках атлант насаживали на палочку, которую втыкали в золу очага со стороны дверей, чтобы утащила какая-нибудь собака. Верили, что от этого шея ребенка будет крепче. В иных случаях засовывали внутрь атланта травинку ${ }^{1}$ и бросали в огонь, три раза читая заклинание Хурай [Бутанаев, Монгуш 2005: 118].

У бурят при разделке туши существовал запрет на угощение гостей шейными позвонками, особенно крайним позвонком со стороны шеи (бур. хара haэp) [Тугутов 1958: 146]. Тувинцы же отвозили несколько шейных позвонков барана с большими отростками отцу, который, в свою очередь, отдавал их своему пастуху. Во время поездок в гости к родителям тувинцы отвозили угощение для двух семей — родителей и брата отца. Для родителей предназначали ужа и все спинные позвонки, примыкающие к ней, левую переднюю и заднюю ногу. Для второй семьи - голову, грудную кость,

${ }^{1}$ Ср.: у калмыков существует традиция разрезания травинки, положенной поперек на корень языка, перед отделением нижней челюсти животного. Перед рассказом о приметах двадцать пятого позвонка барана яс кемәллин эту кость необходимо насадить на палочку. Таким образом осуществляется защита значимых частей туши животного и обеспечивается возможность последующих перерождений. 
правую переднюю и заднюю ноги, колбасу из мяса диафрагмы. Позднее стали делить мясо на три семьи близких родственников, в первую очередь, предназначалось родителей [Потапов 1969: 183].

Еще одним значимым моментом в контексте рассмотрения нами материалов является то, что у тувинцев запрещалось подавать в качестве угощения не только шейные позвонки, но и кости нижней части передних ног. Если шейные позвонки в обрядовой культуре тюрко-монгольских народов семантически связаны с головой, а через нее - верхом, небом, предками и наделением витальностью, то ножки животного - с землей, детьми, родственниками по материнской линии.

У калмыков существует обычай дарения детям бараньей/овечьей голени с копытцем зе бәрльнә йосн родными их матери наһйхн. Перед вручением голень шиир осмаливают, отваривают, затем насаживают на небольшую обструганную палочку. При получении ритуальной голени совершают символический отдарок - дают родственникам монету любого достоинства белого цвета ц̧аһан мөнцгн. В обычае зе бәрлин у калмыков отражаются пережитки авункулата и существовавшие в прошлом имущественные отношения племянников и дяди (брата матери). В условиях кочевого быта, в первую очередь, это был домашний скот.

В свадебном угощении, доставляемом женихом на сторону невесты, везут вареные три голени с копытцем, одну ииир оставляют дома на алтаре. Таким образом, как считается, осуществляется «внедрение» жениха на сторону невесты. В данном случае доставление женихом голени с копытцем можно рассматривать как остаточное проявление пережитков матрилокального брака в прошлом у калмыков [Шараева 2012: 36-39]. У алтайцев жених осуществлял сходный обряд «внесения голени» следующим образом: привезенную тушку овцы подвешивал на коновязь, разделывал, а голень, предварительно обернув внутренним жиром, сжигал, что символизировало совершение им поклонения огню очага невесты и «вхождение» в её семью. Мясо, которое готовил сам, раскладывал на блюде и угощал всех присутствующих [Шатинова 1981:51].

Как отмечают исследователи, мясо барана, его кости, шкура, шерсть, рога в традиционной культуре монгольских народов представляются как обладающие плодо- носящей и очищающей силой, поэтому использование барана в ключевых моментах обрядов жизненного цикла указывает на его особую значимость как «солнечного» животного [Обряды 2002: 134]. Восприятие его как «замены» человека нашло отражение в названии одеяла хүн хүнжэл (букв. 'человек-одеяло'). Для молодоженов «одеяло из 6 шкур шили, при этом верхние головные части шкурок, привезенные стороной жениха, направляли вниз, в то время как шкурки, привезенные стороной невесты шили к головной части, направляя ,шея к шее“ [Очир, Галданова 1988: 113]. Это коррелируется с представлениями о соотнесении невесты в семантическом и обрядовом значениях с головой барана, а жениха - с ногами животного; заложенная в них символика плодородия — с будущим потомством.

Как отмечала Е. Э. Хабунова, после изготовления приданого невесты обязательно произносились благопожелания крепкой и счастливой супружеской жизни в будущем: толһа негдүлжс ('соедините головы', т. е. судьбы), көнжсл хувалщџс ('разделите одеяло’), олн үр-сад hарhжс ('будьте многодетными') [Хабунова 1998: 75].

Через обрядовые действия с бараном/овцой в обрядовой культуре тюрко-монгольских народов достигалось взаимодействие с предками, животное выступало земной проекцией-«заменой» предка. Многочисленные примеры использования частей бараньей туши в различных свадебных обрядах указывают, что через них и «воссоздание» тела предка достигается взаимосвязь для испрашивания покровительства, наделения витальностью, чадородием от него, налаживание связей, необходимых для семейной жизни новобрачных, с божествами и покровителями различных уровней. Так, у уратов Монголии, по сведениям У. Наранбата, шейный позвонок и четыре борцока оставляли в день свадьбы в жилище родителей жениха. На следующее утро их забирали невестка и старшая сноха (монг. бэргэн), сопровождавшая ее для совершения послесвадебных ритуальных действий в жилище родителей мужа. Они открывали дымоход, бэргэн варила чай, который затем раздавала невестка; во время чаепития она получала новое имя [Наранбат 1992: 69].

Оставление четырех борцоков, вероятно, связано с культом предков, так как существует представление, в том числе и у 
калмыков, что человеку от рождения покровительствуют четыре духа-покровителя, по числу предков (два дедушки и две бабушки), а шейный позвонок связан с понятием о даровании жизненной силы предками.

У калмыков существует понятие «трех костей», приносимых в жертву во время жертвоприношения огню, и оставления трех кусков мяса в качестве первинок пищи дееж для угощения душ предков.

Символика числа «7» в этнической культуре калмыков также взаимосвязана с родственными отношениями и предками: семь лепешек привозят на свадьбу для подношения на алтарь, через семь дней душа-сюмсн отходит от тела и отправляется в «иной» мир, достигая его на 49 сутки $(7 \times 7=49)$, почитаются семь звезд созвездия Большой Медведицы, символизирующие предков: семь поколений считаются близкими родственниками, поэтому запрещены браки между их представителями и т. д.

Таким образом, в обрядовой культуре тюрко-монгольских народов, в том числе калмыков, семь шейных позвонков отождествляются с образом предка, с семью поколениями предков и близких родственников, а атлант — с предком-основателем рода.

Жизненная аорта, перебиваемая у жертвенного животного во время забоя и идущая от головы вдоль позвоночника (символизирующая «столб / ось / вертикальную опору», соединяющую миры), семантически отождествляется с красной «нитью жизни» вдоль него.

Шейные позвонки соединяют голову с телом: голова - сакральный центр, верх оси, более близкий к Небу, божествам и покровителям; тело - срединный мир, мир людей, мир родных (каждая из частей туши предназначена определенным родственникам); нижняя часть ног - земля, не только потомство людей и животных, но и вход в «иной» мир.

Первый шейный позвонок — основа этой «оси/столба» в организме человека, с его разрушением прерывается «нить жизни», «дыхание жизни». Эта зависимость отражена в названии другой части позвоночника - от седьмого шейного до поясничных - «душа-спина» (әмн-нурhн). Поэтому «присутствие» предков в брачную ночь, в течение первых трех дней жизни новобрачных связано с получением от них жизненной силы, чадородия и покровительства, в том числе через троекратное вкушение мяса с шейных позвонков. Оформление брачной постели тремя подстилками невесты и жениха и последующее возложение на них одеяла хүн-хүнжсл, в совокупности образующих семь слоев предметов из войлока и шкур барана, формируют своеобразную «утробу», из которой молодожены должны выйти символически «переродившимися» - в ином статусе и жизненном предназначении.

В традиционном жилище калмыков над изголовьем и в ногах семейной кровати подвешивались предметы, символизирующие покровителей. У калмыков, по данным И. Житецкого, на свадьбу доставляли халат лавшг, который подвешивали в кибитке родителей жениха над головной подушкой «он носил название ,элёкци“"» [Житецкий 1893: 22].

В традиционном быту халат лавшг был основным видом одежды у пожилых людей, его носили представители всех социальных групп. На свадьбе старшим представителям рода было принято дарить халат, скроенные части которого сшивались крупными стежками, что позволяло в дальнейшем изготовить одежду нужного размера. По сведениям У. Д. Душана, имеющимся в его архивном фонде в КалмНЦ РАН, в изголовье семейной постели подвешивали өлгц цветные ленты и нити преимущественно красного, синего и белого цветов на белом лоскуте - как подношение и символ предка. «Получение этих ниток и материи указывает предкам, что невеста покинула своих родителей и окончательно стала членом семьи жениха» [НА КалмНЦ РАН. Ф. 6. Оп. 2. Д. 132. Л. 93-94].

Н. Львовский указывал, что и в ногах кровати «прикрепляется к одной из унин небольшой шутен какого-либо бурхана» [Львовский 1893: 13]. В канве современной свадьбы у калмыков невеста привозит набор атрибутов с сакральным значением өлги, истоки которых связывают с добуддийскими верованиями и культом предков, родовыми маркерами. Ленты и нити в өлгц, комбинации которых соответствуют цветам покровителей рода жениха, подвязывают на конец длинного лоскута белой ткани так, чтобы обернуть вложенные монеты, за счет чего моделируется «голова» из монет в узле и «тело» из лоскута, лент и нитей. Хранят өлгц либо на алтаре, либо в изголовье семейной кровати. Белую муж- 
скую рубашку с длинными рукавами и воротом, привозимую невестой вместо халата, дарят самому старшему по статусу мужчине в роду; в отсутствие такового - относят в буддийский храм (хурул) как подношение предкам. У баятов Монголии в цикле послесвадебных обрядов доставляли сырую тушу барана, которую по прибытии «подвешивал к толгой-головке юго-западной решетчатой стенки юрты... „подвешиваемое мясо“ ‘өлгөц мах'» [Очир, Галданова 1992: 49]. Алтайские урянхайцы во время обряда «кормление онгона мясом» подвешивали к решетке юрты на западной стороне жилища целую тушу барана с головой [Эрдэнэболд 2012: 160].

У бурят на свадьбе нерасчлененная туша барана преподносилась как гэрийин хэшэг - «благодать дома» [Обряды 2002: 133]. Поэтому изначальное подвешивание шейных позвонков в правой мужской половине жилища, где расположены атрибуты хозяйственной деятельности, символизирует передачу жизненности по мужской линии предков; чем многочисленнее род, тем крепче родственные связи, возможность взаимопомощи, крепче хозяйство.

Сопоставим общий вид калмыцкого өлгц, завернутого в ткань и образующего подобие антропоморфной модели, с культовыми атрибутами других народов. Онгоны, широко распространенные в прошлом у тюрко-монгольских народов, были изображениями предков и покровителей, которые располагали в определенных частях жилища. Например, у урянхайцев их подвешивали над кроватью: онгон «Емегельджин или Емеген $<.$. > устраивается теми, кто не имеет детей $<\ldots>$ или родятся и умирают $<\ldots>$ состоит из четырехугольного < ...> лоскута, на котором нашиты куколки с руками и ногами (часто их три. - T. Ш.) <..> к животу куколок пришиваются пучки яламы <..> джаламы (цветные лентовидные лоскуты тканей. - T. Ш.) <..> такие же лоскуты пришиты к концам рук вместо обшлагов... Предварительно лоскут опускается в войлочный чехол, который посредством шнурков подвешивается к решетке. Иногда куколки прямо нашиваются внутри войлочного чехла, который тогда имеет один край у отверстия длиннее и закрывается вроде наших портфелей...» [Потанин 2005: 99].

У калмыков представления об онгонах сохранялись вплоть до начала $\mathrm{XX}$ в. Так, калмыки ставили отдельную лампадку «,,онгон-зул“ < . > для злых и черных духов $<\ldots>$ под кровать жены хозяина, полагая, что злые духи живут в женской половине под кроватью» [Кануков 1928: 88].

В современной свадебной обрядности представители некоторых этнических групп калмыков сохранили традицию поклонения данной лампаде, но именуют лампаду шуһуна зул (букв. 'лампада в тайном месте'): после зажжения и совершения ритуала поклонения невесты ее гасят и прячут под кровать, либо дают догореть, но оставляя на полу, где она находилась изначально. Считается, что таким образом невеста вступает под покровительство предков рода жениха.

Рассматривая семантику шейных позвонков барана/овцы — «двойника человека» - необходимо указать некоторые существующие представления у калмыков о вороте одежды. В обрядах, связанных с защитой жизни человека, могла быть использована не вся одежда, а только ее значимая часть, прикрывающая сакральные каналы проникновения в тело человека, через которые можно и положительно, и отрицательно воздействовать на него. В обрядах выкупа жизни человека дмнә долиг калмыки используют ворот одежды, который закапывают на перекрестке дорог.

В традиционном быту на одежде грудных детей ворот вырезали в форме треугольника, который просто откидывали назад, не отрезая по широкой воротниковой части. Для усиления защитных функций в него вкладывали первородные волосы ребенка. Маленьким детям подшивали под/на ворот косточки диких животных, которые издавали звуки при ходьбе, что, согласно поверьям, должно было отпугнуть злых духов. Девушки прикрепляли в воротниковой зоне на косы специальное украшение гижсгъч в надежде защититься от воздействия вредоносных сил.

Позвоночник - основа тела человека. Перелом позвоночника приводит к инвалидности или летальному исходу, перелом основания черепа или шеи - к моментальной смерти, поэтому эту часть тела очень оберегали. Воины - реальные и эпические — обязательно закрывали шейную часть тела дополнительными доспехами. В эпических произведениях тюрко-монгольских народов определенные части скелета характеризуются как сросшиеся или обладающие качеством металла. 
Как считал А. Ш. Кичиков, «идея костяного панциря из сросшихся костей позвоночника и ребер как свойство неуязвимости героя возникла задолго до изобретения металлических доспехов, с появлением которых она трансформировалась в идею металлического тела» [Кичиков, Цуцкин 1997: 70].

Таким образом, шейные позвонки «отвечают» за полноценную жизнедеятельность человека. В этнической культуре калмыков сформировался пласт представлений о шейных позвонках как о каналах, символически открытых в теле человека, требующих реальной и магической защиты.

В пространстве традиционного жилища локализация шейных позвонков во время проведения традиционной свадьбы была обусловлена представлениями о взаимосвязи жертвенного животного как «двойника» человека с культом предков и онгонами. Через обрядовые действия с шейными позвонками достигалась возможность символического контакта с предками для испрашивания жизненности и потомства у них, покровительства и обновление социального статуса, моделирования будущей жизни брачующихся. В современной свадебной обрядности отсутствие обрядовых действий с шеей животного и оставление в семейном пространстве является утратой первоначальных знаний о ней вследствие табуации и ослабления позиций добуддийских верований.

\section{ЛИТЕРАТУРА / REFERENCES}

Бакаева 2009 - Бакаева Э. П. Сакральные коды культуры калмыков. Элиста: ИКИАТ, 2009. 159 c. [Bakaeva E. P. Sakral'nye kody kul'tury kalmykov [Sacral codes of Kalmyk culture]. Elista: Institute for Comprehensive Studies of Arid Territories, 2009. 159 p. (In Rus.)]

Бутанаев, Монгуш 2005 - Бутанаев В. Я., Монгуш Ч. В. Архаические обычаи и обряды саянских тюрков. Абакан: Изд-во Хакасск. гос. ун-та им. Н. Ф. Катанова, 2005. 200 с.; ил. [Butanaev V. Ya., Mongush Ch. V. Arkhaicheskie obychai $i$ obryady sayanskikh tyurkov [Turkic peoples of the Sayan mountains: archaic customs and rituals]. Abakan: Khakass State Univ., 2005. 200 p. (In Rus.)]

Вяткина 1960 - Вяткина К. В. Монголы Монгольской Народной Республики (Материалы историко-этнографической экспедиции Академии наук СССР и Комитета наук MHP 1948-1949 гг.) // Восточно-Азиатский этнографический сборник. М.; Л.: Изд-во Академии наук CCCP, 1960. C. 159-271. [Vyatkina K. V. Mongols of the Mongolian People's Republic (materials of the 1948-1949 historical and ethnographic expedition by the USSR Acad. of Sciences and the MPR Committee for Science). Vostochno-Aziatskiy etnograficheskiy sbornik. Moscow; Leningrad: USSR Acad. of Sc., 1960. Pp. 159-271. (In Rus.)]

Душан 2016 - Душан У. Д. Избранные труды. Элиста: КИГИ РАН, 2016. 376 c. [Dushan U. D. Izbrannye trudy [Selected works]. Elista: Kalmyk Humanities Research Institute of RAS, 2016. 376 p. (In Rus.)]

Житецкий 1893 - Житецкий И. А. Очерки быта астраханских калмыков (этнографические наблюдения 1884-1886 гг.). М.: Тип. М. Г. Волчанинова, 1893. 87 с.; Репринтное издание. Элиста: Калм. гос. галерея, 1991. 73 c. [Zhitetsky I. A. Ocherki byta astrakhanskikh kalmykov (etnograficheskie nablyudeniya 1884-1886 gg.) [Essays on everyday life of Astrakhan Kalmyks (ethnographic observations of 1884-1886)]. Moscow: M. G. Volchaninov, 1893. 87 p.; Reprint ed. Elista: Kalm. State Gallery, 1991. 73 p. (In Rus.)]

Кануков 1928 - Кануков Х. Б. Галын Окн тенгр. Огнепоклонство у ламаитов-буддистов // Калмыцкая степь. 1928. № 8-9 (№ 11-12). C. 83-89. [Kanukov Kh. B. Galyn Okn ten$g r$. Fire-worship among Lamaist Buddhists. Kalmytskaya step'. 1928. No. 8-9 (No. 11-12). Pp. 83-89. (In Rus.)]

Кичиков, Цуцкин 1997 - Кичиков А. Ш., Цуикин $E$. $B$. Археологические параллели некоторых мотивов эпоса «Джангар» // Проблемы современного джангароведения. Кн. 1. Элиста, 1997. С. 63-79. [Kichikov A. Sh., Tsutskin E. V. The epic of Jangar: archaeological parallels of some motifs. Problemy sovremennogo dzhangarovedeniya [Challenges of present-day Jangar studies]. Book 1. Elista, 1997. Pp. 63-79. (In Rus.)]

Лхагвасурэн 2013 - Лхагвасурэн И. Алтайские урянхайцы. Историко-этнографические очерки (конец XIX - начало XX в.). Улан-Удэ: БНЦ СО РАН, 2013. 178 с. [Lkhagvasuren I. Altayskie uryankhaytsy. Istoriko-etnograficheskie ocherki (konets XIXnachalo $X X v$.) [The Altai Uriankhai. Historical and ethnographic essays (late $19^{\text {th }}$ - early $20^{\text {th }}$ cc.)]. Ulan-Ude: Buryat Scientific Center (Siberian Branch) of RAS, 2013. 178 p. (In Rus.)]

Львовский 1893 - Львовский Н. Калмыки Большедербетовского улуса Ставропольской губернии и калмыцкие хурулы: происхождение и история // Ученые записки императорского Казанского университета. Казань: 
Типо-литография Императорского Университета, 1893. 119 c. [Lvovsky N. Kalmyks of Iki Dorbet Ulus (district) of Stavropol Governorate and Kalmyk Buddhist temples: origins and history. Uchenye zapiski imperatorskogo Kazanskogo universiteta. Kazan: Imperial Kazan Univ., 1893. 119 p. (In Rus.)]

Наранбат 1992 - Наранбат У. Свадебный обряд уратов Внутренней Монголии // Традиционная обрядность монгольских народов. Новосибирск: Наука, 1992. С. 56-71. [Naranbat U. The Urads of Inner Mongolia: wedding rites. Traditsionnaya obryadnost' mongol'skikh narodov [Traditional rituals of Mongolic peoples]. Novosibirsk: Nauka, 1992. Pp. 56-71. (In Rus.)]

Небольсин 1852 - Небольсин П. И. Очерки быта калмыков Хошеутовского улуса. СПб.: Типография Карла Крайя, 1852. 192 с. [Nebolsin P. I. Ocherki byta kalmykov Khosheutovskogo ulusa [Kalmyks of Khosheutovsky Ulus: sketches of everyday life]. St. Petersburg: Karl Kray, 1852. 192 p. (In Rus.)]

Обряды 2002 - Обряды в традиционной культуре бурят. М.: Вост. лит, 2002. 222 с. [Obryady v traditsionnoy kul'ture buryat [Rituals in traditional Buryat culture]. Moscow: Vost. Lit, 2002. 222 p. (In Rus.)]

Очир, Галданова 1992 - Очир А., Галданова Г. Р. Свадебная обрядность баятов МНР // Традиционная обрядность монгольских народов. Новосибирск: Наука, 1992. С. 2456. [Ochir A., Galdanova G. R. The Bayads of Mongolia: wedding rites. Traditsionnaya obryadnost' mongol'skikh narodov. Novosibirsk: Nauka, 1992. Pp. 24-56. (In Rus.)]

Очир, Галданова 1988 - Очир А., Галданова Г. Р. Традиционная семейная обрядность мингатов МНР // Культурно-бытовые традиции бурят и монголов. Улан-Удэ: БФ CO AH CCCP, 1988. C. 109-127. [Ochir A., Galdanova G. R. The Myangads of Mongolia: wedding rites. Kul'turno-bytovye traditsii buryat $i$ mongolov. Ulan-Ude: Buryat Research Institution (Siberian Branch) of USSR Acad. of Sc., 1988. Pp. 109-127. (In Rus.)]

Потапов 1969 - Потапов Л. П. Очерки народного быта тувинцев. М.: Наука, 1969. 402 с. [Potapov L. P. Ocherki narodnogo byta tuvintsev [The Tuvans: sketches about folk household activities]. Moscow: Nauka, 1969. 402 p. (In Rus.)]

Потанин 2005 - Потанин Г. Н. Очерки Северо-Западной Монголии. Изд. 2-е. ГорноАлтайск: Ак-Чечек, 2005. 1026 с.; илл. и табл. Репринт: Потанин Г. Н. Очерки Северо-Западной Монголии. СПб.: Тип. В.
Киршбаума, 1883. [Potanin G. N. Ocherki Severo-Zapadnoy Mongolii [Essays on Northwest Mongolia]. $2^{\text {nd }}$ ed. Reprint. Gorno-Altaysk: Ak-Chechek, 2005. 1026 p. (In Rus.)]

Тугутов 1958 - Тугутов И. Е. Материальная культура бурят. Улан-Удэ: БКНИИ, 1958. 215 c. [Tugutov I. E. Material'naya kul'tura buryat [Material culture of the Buryats]. UlanUde: Buryat Inst. for Comprehensive Research, 1958. 215 p. (In Rus.)]

Хабунова 1998 - Хабунова E. Э. Калмыцкая свадебная обрядовая поэзия. Элиста: Калм. кн. изд-во, 1998. 224 с. [Khabunova Е. Е. Kalmytskaya svadebnaya obryadovaya poeziya [Kalmyk wedding: ceremonial poetry]. Elista: Kalm. Book Publ., 1998. 224 p. (In Rus.)]

Шараева 2015 - Шараева Т. И. Субпродукты в обрядовой культуре калмыков // Актуальные проблемы современного монголоведения. Элиста: КИГИ РАН, 2015. С. 74-84. [Sharaeva T. I. By-products in ceremonial culture of the Kalmyks. Aktual'nye problemy sovremennogo mongolovedeniya [Topical issues of present-day Mongol studies]. Elista: Kalmyk Humanities Research Institute of RAS, 2015. Pp. 74-84. (In Rus.)]

Шараева 2012 - Шараева Т. И. Обычай «зе бәрлһн» у калмыков // Вестник Калмыцкого университета. 2012. № 4. С. 36-39. [Sharaeva T. I. The Kalmyk ritual of 'ze bärlyn'. Vestnik Kalmyckogo gosudarstvennogo universiteta [Bulletin of Kalmyk University]. 2012. No. 4. Pp. 36-39. (In Rus.)]

Шатинова 1981 - Шатинова Н. И. Семья у алтайцев. Горно-Алтайск: Горно-Алтайское отделение Алтайск. кн. изд-ва, 1981. 184 с. [Shatinova N. I. Sem'ya u altaytsev [The Altaian family]. Gorno-Altaysk: Altay Book Publ., 1981. 184 p. (In Rus.)]

Эрдниев 1970 - Эрдниев У. Э. Калмыки. Историко-этнографические очерки (конец XIX - начало XX). Элиста: Калм. кн. изд-во, 1970. 312 c. [Erdniev U. E. Kalmyki. Istorikoetnograficheskie ocherki (konets XIX-nachalo $X X)$ [The Kalmyks: historical and ethnographic essays (late $19^{\text {th }}-$ early $20^{\text {th }} \mathrm{cc}$.)]. Elista: Kalm. Book Publ., 1970. 312 p. (In Rus.)]

Эрендженов 1980 - Эрендженов К. Э. Родник мудрости (на калм. яз.). Элиста: Калм. кн. изд-во, 1980. 188 с. [Erendzhenov K. E. Rodnik mudrosti [The Spring of Wisdom]. Elista: Kalm. Book Publ., 1980. 188 p. (In Kalm.)]

Эрдэнэболд 2012 - Эрдэнэболд Л. Традиционные верования ойрат-монголов (конец XIX - начало XX в.). Улан-Удэ: Изд- 
во БНЦ СО РАН, 2012. 196 с. [Erdenebold L. Traditsionnye verovaniya oyrat-mongolov (konets $X I X$ - nachalo $X X$ v.) [Traditional be- liefs of the Oiyirad Mongols (late $19^{\text {th }}-$ early $20^{\text {th }}$ cc.)]. Ulan-Ude: Buryat Scientific Center (Sib. Branch) of RAS, 2012. 196 p. (In Rus.)]

\title{
'And the 'Bad' Neck We Shall Leave Back at Home...' (Symbolism of Sheep Neck Bones within Kalmyk Wedding Rites Revisited)
}

\section{Tatyana I. Sharaeva ${ }^{1}$}

${ }^{1}$ Ph.D. in History (Cand. of Historical Sc.), Senior Research Associate, Department of History, Ethnology and Archaeology, Kalmyk Scientific Center of the RAS (8, Ilishkin St., Elista, 358000 Russian Federation). ORCID: 0000-0002-2242-5136. E-mail: sharaevati@yandex.ru

\begin{abstract}
The article examines the symbolism of sheep neck bones in Kalmyk wedding rites. According to present-day wedding procedures, sheep neck bones should by all means be left behind within home space which results from a belief that those are somewhat 'bad' meat unsuitable for any ceremonial meals, and can be consumed as routine food only. The available sources on Kalmyk ceremonial culture contain no data that would clarify the role of sheep neck bones and related procedures. Still, an insight into wedding rites of the Turco-Mongols (viewed as comparative reference materials) made it possible to reveal the semantics of neck bones attributed to sacrificed animals and, thus, reconstruct some related activities in the context of traditional wedding rituals.

Ceremonial cultures of the Turco-Mongols — including that of the Kalmyks - associate the seven neck bones with the image of the Ancestor, the seven generation of ancestors and close relatives, and the atlas (the first cervical vertebra) stands for the progenitor (clan founder) as such. The animal's aorta to be ruptured during a ritualistic sacrifice slaughter lies along the spine ("pillar / axe / vertical support') which is a bridge between the three worlds, and, so, the former semantically acts as a 'fatal thread of life'. Neck bones join the head and the body: the head is a sacral center (the top of the axe) to contact the Heaven, Gods and protector-deities; the body stands for the middle world of humans, relatives (each part of the animal to be strictly delivered to certain relatives); the lower part of the body, legs, are related to the earth with animal and human off-springs, and also viewed as an entrance into the 'other' world.

The first cervical vertebra is the founding element of the 'axe / pillar', and once it gets destroyed the 'thread of life', 'breath of life' comes to its end. The paper concludes that the allocation of neck bones throughout the traditional home during ritualistic wedding offerings of the Kalmyks was actually determined by ancient beliefs about interrelation between a sacrificed animal and the cult of ancestors, especially the ongons that had been eradicated by Buddhist clerics by the late $19^{\text {th }}$ century.

The numerous patterns of use of sheep body parts in different wedding ceremonies indicate that inter alia those serve to 'reconstruct' the ancestor's body and thus establish a 'channel' to deliver requests for protection, vitality, childbirth, and assistance in building connections between the newly married and multi-leveled Gods, protector-deities which would guarantee happiness for the young family in future. So, the neck bones are 'responsible' for sound human life and activities. As a result, ethic culture of the Kalmyks developed a layer of beliefs according to which neck bones serve as symbolically open (energy) channels of the human body that require both real and magic protection means.

The fact that contemporary Kalmyk wedding rites include no rituals to use animal neck parts and the stipulation to leave (consume) the latter behind in home space only testifies of a loss of once tabooed initial knowledge.
\end{abstract}

Keywords: Kalmyks, wedding rites, zoolatrous cults, sheep, neck bones 